\title{
PENGANGKUTAN KAYU MENGGUNAKAN LIMA JENIS TRUK DI DUA HUTAN TANAMAN INDUSTRI DI SUMATERA
}

\section{(Log Hauling Uses Five Types of Trucks in Two Industrial Plantation Forest in Sumatera)}

Oleh/By:

\section{Sukadaryati}

Pusat Litbang Hasil Hutan, Jl. Gunung Batu No. 5 Bogor Telp./Fax. 863337/8633413

Diterima 8 Agustus 2008, disetujui 20 Januari 2009

\begin{abstract}
Log bauling is aimed at bringing logs to the destination on time continually. Log hauling in plantation forest is usually done by using logging truck. This paper aimed at knowing productivity, cost, time efficiency and optimum performance of log hauling using five types of truck in two industrial plantation forests in Sumatera.

The results showed that productivity of log hauling by using Volvo 380, Mitsubishi PS220/260, Hino PS260, Mercedes Benz 2631 dan Mitsubishi PS120/135 truks were $582.508 \mathrm{~m}^{3} . \mathrm{km} /$ hour; $465.058 \mathrm{~m}^{3} . \mathrm{km} /$ hour, 459.660 $\mathrm{m}^{3} . \mathrm{km} /$ hour; $309.540 \mathrm{~m}^{3} . \mathrm{km} /$ bour and $194.148 \mathrm{~m}^{3} . \mathrm{km} /$ bour, respectively. The cost of log bauling using those truks were $\mathrm{Rp} 949.630 / \mathrm{m}^{3} . \mathrm{km} ; \mathrm{Rp} 585.165 / \mathrm{m}^{3} . \mathrm{km} ; \mathrm{Rp} 619.265 / \mathrm{m}^{3} . \mathrm{km}, \mathrm{n} \mathrm{Rp} 1,686.553 / \mathrm{m}^{3} . \mathrm{km}$ and $\mathrm{Rp}$ $1,403.864 / \mathrm{m}^{3} . \mathrm{km}$, respectively. Their time efficiency were $79.26 \% ; 77.92 \% ., 73.40 \% ; 76.69 \%$ and $87.42 \%$, respectively. The optimum performance of log hauling was obtained by using Volvo 380 and Mitsubishi 220/260 truks.
\end{abstract}

Keywords: Log hauling, productivity, cost, efficiency and optimum performance

\section{ABSTRAK}

Pengangkutan kayu berguna untuk mengantarkan kayu ke tempat tujuan pada waktu yang tepat secara kontinyu. Pengangkutan kayu melewati jalan darat di hutan tanaman biasanya dilakukan dengan menggunakan truk angkut. Tulisan ini bertujuan untuk mengetahui produktivitas, biaya, efisiensi waktu dan prestasi optimum pengangkutan kayu menggunakan lima truk di dua perusahaan hutan tanaman industri di Sumatera.

Hasil yang diperoleh menunjukkan bahwa produktivitas pengangkutan kayu menggunakan truk jenis Volvo 380, Mitsubishi PS220/260, Hino PS260, Mercedes Benz 2631 dan Mitsubishi PS120/135 berturut-turut sebesar 582,508 $\mathrm{m}^{3} \mathrm{~km} / \mathrm{jam} ; 465,058 \mathrm{~m}^{3} \mathrm{~km} / \mathrm{jam}, 459,660 \mathrm{~m}^{3} \mathrm{~km} / \mathrm{jam} ; 309,540$ $\mathrm{m}^{3} \mathrm{~km} / \mathrm{jam}$ dan $194,148 \mathrm{~m}^{3} \mathrm{~km} / \mathrm{jam}$. Biaya pengangkutan kayu menggunakan truk Mitsubishi PS220/260, Hino PS260, Volvo 380, Mitsubishi PS120/135 dan Mercedes Benz 2631 berturut-turut

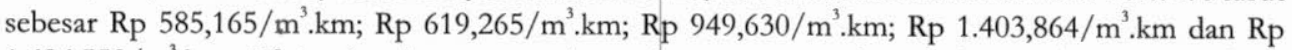
$1.686,553 / \mathrm{m}^{3} . \mathrm{km}$. Efisiensi waktu pengangkutan kayu menggunakan truk Mitsubishi PS120/135, Volvo 380, Mitsubishi PS220/260, Mercedes Benz 2631 dan Hino PS260 berturut-turut sebesar $87,42 \% ; 79,26 \% ; 77,92 \% ., 76,69 \%$ dan $73,40 \%$. Prestasi optimum pengangkutan kayu dicapai bila menggunakan truk merk Volvo 380 dan Mitsubishi 220/260.

Kata kunci: Pengangkutan kayu, produktivitas, biaya, efisiensi dan prestasi optimum 


\section{PENDAHULUAN}

Pengangkutan kayu merupakan kegiatan pemindahan kayu dari tempat pengumpulan sementara di tepi hutan ke tempat pengolahan atau tempat pemasaran melalui jalan yang telah dipersiapkan secara optimal. Pengangkutan kayu bertujuan agar kayu dapat sampai di tempat tujuan pada waktu yang tepat secara kontinyu dengan biaya minimal (Elias, 1988).

Kegiatan pengangkutan kayu dimulai setelah kegiatan memuat kayu ke atas truk selesai dilakukan di tempat pengumpulan kayu sementara di tepi hutan ke tempat pengolahan kayu lebih lanjut atau ke TPK. Kegiatan pengangkutan kayu merupakan kegiatan yang menentukan karena biaya pengangkutan kayu merupakan bagian terbesar, yaitu sekitar $50-90 \%$ dari biaya pembalakan (Widarmana dan Oka, 1972 dalam Sianturi, 1981).

Pengangkutan kayu yang lazim dilakukan di hutan tanaman menggunakan truk dengan kapasitas 1030 ton. Faktor-faktor yang mempengaruhi besarnya produktivitas angkutan truk adalah iklim, kondisi sosial ekonomi, kondisi hutan dan sistem angkutannya sendiri (Sianturi, 1981). Produktivitas pengangkutan kayu dari hutan ditentukan oleh jarak angkut, kecepatan rata-rata, muatan efektif, dan metode muat bongkar (Anonim, 1974). Bila truk tidak melalui jalan umum maka muatan efektif ditentukan oleh keadaan jalan dan jenis truk yang digunakan. Kegiatan muat bongkar perlu diperhatikan juga karena keefektivan muat bongkar sangat mempengaruhi besar kecilnya biaya pengangkutan dari dan ke pabrik. Beberapa faktor yang mempengaruhi cara dan teknik pengangkutan perlu diperhatikan, yaitu : letak dan topografi lapangan; geologi, keadaan tanah dan iklim; luas daerah yang akan dipanen; jumlah dan ukuran kayu; keadaan jalan; dan jarak dan biaya angkutan.

Pada dasarnya pengangkutan kayu yang dilakukan di hutan tanaman tidak jauh berbeda dengan di hutan alam. Namun demikian besarnya produktivitas pengangkutan kayu menggunakan truk di hutan tanaman belum tercatat. Sebagai contoh, produktivitas pengangkutan kayu di hutan alam menggunakan truk merk Mercedes Benz dan merk Nissan masing-masing sebesar 784,09 $\mathrm{m}^{3} . \mathrm{km} / \mathrm{jam}$ dan $987,87 \mathrm{~m}^{3} . \mathrm{km} /$ jam (Dulsalam dan Arifin S, 1997). Produktivitas truk merk Nissan semi trailer (280 HP), logging truk Berliet semi trailer (280 HP) dan Nissan (125 HP) yang digunakan untuk mengangkut kayu di hutan alam masing-masing sebesar 484,99 $\mathrm{m}^{3} \cdot \mathrm{km} / \mathrm{jam} ; 492,07 \mathrm{~m}^{3} \cdot \mathrm{km} / \mathrm{jam}$ dan $292,07 \mathrm{~m}^{3} \cdot \mathrm{km} / \mathrm{jam}$ (Sukanda, et al., 1989). Sianturi dan Tinambunan (1985) menyatakan bahwa produktivitas truk semi trailer di Provinsi Jambi, Riau, Sumatera Selatan dan Kalimantan Selatan berkisar antara $265841 \mathrm{~m}^{3} . \mathrm{km} / \mathrm{jam}$ dengan rata-rata $493 \mathrm{~m}^{3} . \mathrm{km} / \mathrm{jam}$, sedang produktivitas truk biasa di provinsi tersebut berkisar antara $91-361 \mathrm{~m}^{3} . \mathrm{km} / \mathrm{jam}$ dengan rata-rata $247 \mathrm{~m}^{3} \cdot \mathrm{km} / \mathrm{jam}$.

Efisiensi waktu pengangkutan kayu merupakan nilai relatif antara waktu efektif yang digunakan untuk mengangkut kayu terhadap waktu total yang diperlukan untuk mengangkut kayu tersebut dan dinyatakan dalam persen (\%). Waktu efektif merupakan waktu yang digunakan alat angkut (truk) untuk mengangkut kayu dari tempat pengumpulan kayu di tepi hutan sampai ke tempat pengolahan kayu. Sementara itu, waktu total adalah jumlah waktu keseluruhan yang digunakan untuk mengangkut kayu, yang terdiri dari waktu efektif pengangkutan dan waktu lain-lain. Waktu lain-lain adalah waktu di luar waktu efektif yang diperlukan selama proses pengangkutan kayu menuju ke tempat tujuan. Waktu lain-lain biasa digunakan oleh operator pengangkut kayu untuk mengisi bahan bakar, memperbaiki 
kerusakan alat, mengatasi gangguan-gangguan lain yang timbul di sepanjang jalan dan istirahat.

Seperti halnya produktivitas pengangkutan kayu, tingkat efisiensi waktu pangangkutan kayu di hutan tanaman belum tercatat. Sebagai contoh, tingkat efisiensi pengangkutan kayu di hutan alam dengan truk merk Mercedes Benz dan merk Nissan masing-masing sebesar 53,22\% dan 57,71\% (Dulsalam dan Arifin S, 1997).

Dalam tulisan ini disajikan hasil penelitian tentang produktivitas, efisiensi dan biaya pengangkutan kayu menggunakan lima jenis truk di hutan tanaman industri serta memilih truk yang menghasilkan prestasi yang optimum. Hasil yang diperolah diharapkan dapat digunakan sebagai acuan dalam kegiatan pengangkutan kayu di hutan tanaman.

\section{METODE PENELITIAN}

\section{A. Lokasi dan Waktu Penelitian}

Penelitian dilakukan di Hutan Tanaman Industri (HTI) yang kayunya dijadikan sebagai bahan baku pulp, yaitu masing-masing di satu perusahaan di Sumatera Selatan dan Provinsi Jambi. Pengumpulan data lapangan dilakukan pada bulan Juni dan September 2006.

\section{B. Bahan dan Alat Peneltian}

Bahan dan alat yang digunakan untuk penelitian ini adalah : truk angkut (Volvo 380, Mitsubishi PS220/260, Hino PS260, Mercedes Benz 2631 dan Mitsubishi PS120/135), solar, minyak pelumas, aki $100 \mathrm{~A}$, cat, kuas, pita meter, chinometer, stop watch, alat tulis, komputer dan meteran.

\section{Prosedur Penelitian}

1. Pengumpulan data primer: Setiap pengamatan pengangkutan dicatat volume kayu yang diangkut, jarak angkut $(\mathrm{km})$, waktu efektif pengangkutan dan waktu lain-lain. Waktu efektif dan waktu lain-lain pengangkutan tersebut diukur dengan alat pengukur waktu

$\therefore$ (stop watch). Waktu lain-lain yang dicatat adalah waktu yang terbuang akibat gangguan alat, waktu istirahat, pengisian bahan bakar, ataupun gangguan lain yang mungkin timbul pada saat kegiatan pengangkutan kayu berlangsung.

2. Pengumpulan data sekunder : mencatat kondisi umum areal hutan tanaman, rencana produksi dan realisasi produksi kayu tahunan, upah pekerja yang diberlakukan saat itu, industri kayu yang dimiliki serta harga dan spesifikasi alat pengangkutan kayu yang digunakan.

\section{Pengolahan Data}

Data yang telah dikumpulkan dipakai sebagai dasar perhitungan untuk menentukan mean (rata-rata). Nilai mean yang diperoleh kemudian dianalisis dan dikaji lebih lanjut untuk mendapatkan hasil sesuai tujuan dan sasaran. Adapun rumus yang digunakan adalah sebagai berikut (Dulsalam dan Arifin S, 1997): 
1. Produktivitas alat angkut dihitung dengan rumus :

$$
\mathrm{Pa}=\frac{\mathrm{Va} \times J \mathrm{a}}{\mathrm{Wa}}
$$

dimana $: \mathrm{Pa}=$ Produktivitas alat angkut $\left(\mathrm{m}^{3} \cdot \mathrm{km} / \mathrm{jam}\right) ; \mathrm{Va}=$ jumlah volume $\mathrm{kayu}$ yang diangkut per rit $\left(\mathrm{m}^{3}\right) ; \mathrm{Ja}=$ jarak angkut; Wa $=$ Waktu efektif pengangkutan (jam)

2. Volume kayu yang dimuat bongkar dan diangkut dihitung dengan rumus :

$$
\mathrm{V}=1 / 4 \mathrm{D}^{2} \times \mathrm{L}
$$

dimana : $\mathrm{V}=$ Volume kayu $\left(\mathrm{m}^{3}\right) ; \mathrm{D}=$ Diameter rata-rata (pangkal dan ujung) kayu (m); L= Panjang kayu (m)

3. Efisiensi waktu pengangkutan :

$$
E=\frac{W e}{W t} \times 100 \%
$$

dimana $: \mathrm{E}=$ Efisiensi $(\%)$; We $=$ Waktu efektif $($ menit atau jam); Wt $=$ Waktu total (menit atau jam)

Biaya yang dihitung dibedakan menjadi biaya tetap dan biaya tidak tetap. Biaya tetap adalah biaya penyusutan, biaya asuransi, bunga dan pajak, sedang biaya tidak tetap meliputi biaya bahan bakar, pelumas, perawatan dan perbaikan, suku cadang dan tenaga kerja. Biaya penyusutan dan biaya perawatan alat dihitung berdasarkan Weckerman (1949). Biaya bunga modal, pajak, asuransi, bahan bakar, oli dan pelumas serta upah operator dihitung dengan formula FAO (Anonim, 1992).

\section{HASIL DAN PEMBAHASAN}

\section{A. Gambaran Umum Lokasi Penelitian}

Jenis kayu yang diangkut adalah kayu akasia (Acacia mangium) yang digunakan sebagai bahan baku pembuatan pulp (bubur kayu). Kayu akasia tersebut dipanen pada umur kurang lebih 6 tahun (tahun tanam 2000) dengan diameter antara 8-60 cm dan umur 4 tahun (tahun tanam 2002) dengan diameter antara $8-45 \mathrm{~cm}$.

Kegiatan pengangkutan kayu dimulai setelah kayu hasil tebangan dipotong-potong sesuai dengan sortimen yang diinginkan dan dikumpulkan terlebih dahulu di pinggir hutan dekat dengan jalan angkutan. Pengumpulan kayu ini dilakukan dengan alat Timberjack, sedang tujuan pengumpulan kayu di tepi hutan tersebut adalah untuk memudahkan proses pemuatan dan pengangkutan kayu. Mula-mula tumpukan kayu dimuat ke atas truk angkut dengan 
menggunakan alat muat kayu mekanis (loader). Kemudian dilakukan pengaturan kayu dan pengikatan muatan kayu dengan alat panset (biasanya panjangnya $10 \mathrm{~m}$ ) agar kayu tersusun rapi dan aman (tidak berceceran) saat diangkut. Setelah pengikatan selesai, kayu siap diangkut ke tempat tujuan.

Lima jenis truk yang digunakan adalah truk merk Mercedes Benz 2631, Volvo 380, Mitsubishi PS120/135, Mitsubishi PS220/260 dan Hino PS260. Truk angkut tersebut sebagian besar bukan milik perusahaan tempat penelitian tetapi milik kontraktor (tempat penyewaan alat berat) dan perusahaan hanya menyewanya selama kegiatan pengangkutan kayu berlangsung. Oleh karena itu data spesifik truk, seperti tahun pembuatan, harga alat, bahkan harga sewa truk tidak tersedia secara lengkap. Namun demikian berdasarkan pengamatan langsung di lapangan dan wawancara dengan pengemudi truk dapat diperoleh beberapa data sekunder yang bisa diacu.

Truk merk Mercedes Benz 2631 mempunyai tenaga motor sekitar 200 HP dan terdiri dari 2 buah gandengan, sedang truk merk Volvo 380 bertenaga motor sekitar $400 \mathrm{HP}$ dan terdiri dari 5 buah gandengan. Ukuran masing-masing gandengan truk Mercedes Benz 2631 adalah lebar $280 \mathrm{~m}$ dan tinggi $210 \mathrm{~m}$, sedang ukuran masing-masing gandengan truk Volvo 380 adalah lebar $220 \mathrm{~m}$ dan tinggi $230 \mathrm{~m}$. Kapasitas truk merk Mercedes Benz 2631 sebesar 20 ton/rit sedang truk merk Volvo 380 berkapasitas 40 ton/rit. Berdasarkan pengamatan di lapangan, jumlah kayu yang dapat diangkut truk Mercedes Benz 2631 (2 gandengan) sebesar 240-300 batang kayu, sedang truk Volvo 380 (5 gandengan) sebesar 480-600 batang kayu. Sementara itu, truk merk Mitsubishi PS120/135 berkapasitas 10 ton/rit sedang truk merk Mitsubishi PS260 dan Hino PS260 berkapasitas 30 ton/rit.

Topografi lapangan tempat penelitian termasuk landai, yaitu kemiringan antara $8-15 \%$. Jenis tanah di areal tersebut adalah podsolik merah kuning. Jalan utama yang dilalui truk angkut sebagaian besar telah diperkeras dengan sistem macadam sedang aksesibilitas sekitar areal hutan cukup tinggi karena dekat dengan perkampungan penduduk. Jalan utama maupun jalan cabang yang belum diperkeras dengan baik akan becek dan licin saat hujan tiba dan berdebu saat musim kemarau. Lebar jalan utama $10 \mathrm{~m}$ sedang jalan cabang berkisar 6-8 $\mathrm{m}$.

Pengemudi truk yang digunakan diambil secara acak. Umur rata-rata pengemudi berkisar antara 25-45 tahun, kondisi badan sehat dan berjenis kelamin laki-laki. Rata-rata sudah berpengalaman menjadi pengemudi truk selama 3-6 tahun.

Letak areal hutan yang dekat dengan penduduk, sangat menguntungkan perusahaan. Sebagian besar (tidak kurang dari $80 \%$ ) tenaga kerja yang ada di perusahaan berasal dari masyarakat setempat.

\section{B. Produktivitas Pengangkutan Kayu}

Produktivitas pengangkutan kayu menggunakan truk dijabarkan sebagai kemampuan truk untuk mengangkut kayu $\left(\mathrm{m}^{3}\right)$ melalui jarak angkut tertentu $(\mathrm{km})$ per satuan waktu (jam), atau dinyatakan sebagai $\mathrm{m}^{3} . \mathrm{km} / \mathrm{jam}$. Pada tabel 1 disajikan data hasil kegiatan pengangkutan kayu dengan lima jenis truk yang dioperasikan di HTI. 
Tabel 1. Data pengangkutan kayu menggunakan lima jenis truk di HTI Table 1. Data of log bauling using five types of truck in HTI

\begin{tabular}{|c|c|c|c|c|c|}
\hline No & $\begin{array}{c}\text { Jenis } \\
\text { truk/Type of } \\
\text { truck }\end{array}$ & $\begin{array}{l}\text { Volume kayu/ } \\
\text { Log volume }\left(\mathrm{m}^{3}\right)\end{array}$ & $\begin{array}{l}\text { Waktu efektif } \\
\text { pengangkutan/ } \\
\text { Effective bauling } \\
\text { time (jam/ hour) }\end{array}$ & $\begin{array}{c}\text { Jarak / } \\
\text { Distance } \\
(\mathrm{km})\end{array}$ & $\begin{array}{c}\text { Produktivitas/ } \\
\text { Productivity } \\
\left(\mathrm{m}^{3} \cdot \mathrm{km} / \text { jam/ }\right. \\
m^{3} \cdot \mathrm{km} / \text { hour) }\end{array}$ \\
\hline \multirow[t]{2}{*}{1.} & \multirow{2}{*}{$\begin{array}{l}\text { Mercedes } \\
\text { Benz } 2631\end{array}$} & $K: 15,750-17,000$ & $K: 3,38-3,62$ & K: $66-67,2$ & $\mathrm{~K}: 291,982-327,724$ \\
\hline & & $\mathrm{R}: 16,417$ & R: 3,51 & R: 66,2 & R: 309,540 \\
\hline \multirow[t]{2}{*}{2.} & \multirow[t]{2}{*}{ Volvo 380} & $\mathrm{~K}: 33,600-33,750$ & $K: 3,83-4,12$ & K: $64-67,3$ & K: 542,769-624,508 \\
\hline & & $\mathrm{R}: 35,041$ & R: 4,04 & R: 66,8 & R: 582,487 \\
\hline \multirow[t]{2}{*}{3.} & \multirow{2}{*}{$\begin{array}{l}\text { Mitsubishi } \\
\text { PS120/135 }\end{array}$} & $\mathrm{K}: 7,334-8,980$ & $K: 6,51-6,80$ & K: $150-175$ & $\mathrm{~K}: 170,635-211,164$ \\
\hline & & $\mathrm{R}: 8,103$ & R: 6,69 & R: 160,43 & $\mathrm{R}: 194,148$ \\
\hline \multirow[t]{2}{*}{4.} & \multirow{2}{*}{$\begin{array}{l}\text { Mitsubishi } \\
\text { PS220/260 }\end{array}$} & K: $28,771-29,864$ & $K: 2,29-3,05$ & $K: 36-50$ & $\mathrm{~K}: 368,155-650,713$ \\
\hline & & R: 29,858 & R: 2,87 & R: 43 & R: 459,660 \\
\hline \multirow[t]{2}{*}{5.} & \multirow{2}{*}{$\begin{array}{l}\text { Hino PS } \\
260\end{array}$} & K: $28,411-30,791$ & K: 2,99-4,49 & $\mathrm{K}: 44-73$ & $\mathrm{~K}: 439,305-516,963$ \\
\hline & & R: 29,747 & $\mathrm{R}: 3,58$ & R: 56,4 & R: 465,058 \\
\hline
\end{tabular}

Keterangan (Remarks) : $\mathrm{K}=$ kisaran (range), $\mathrm{R}=$ rata-rata (average), jumlah ulangan pengamatan (number of replicates) $=47$

Rata-rata volume kayu yang diangkut menggunakan truk jenis Mercedes Benz 2631; Volvo 380; Mitsubishi PS 120/135; Mitsubishi PS 220/260 dan Hino PS 260 masing-masing sebesar $16,417 \mathrm{~m}^{3} /$ rit; 35,$041 ; 8,103 \mathrm{~m}^{3} /$ rit; $29,858 \mathrm{~m}^{3} /$ rit dan $29,747 \mathrm{~m}^{3} /$ rit (Tabel 1). Kisaran volume selengkapnya untuk masing-masing jenis truk dapat dilihat pada Tabel 1. Besar kecilnya volume kayu yang diangkut tergantung pada kapasitas truk yang digunakan yang pada akhirnya akan mempengaruhi produktvitas alat yang digunakan.

Jarak rata-rata yang ditempuh truk merk Mercedes Benz 2631, Volvo 380, Mitsubishi PS120/135; Mitsubishi PS220/260 dan Hino PS260 masing-masing sepanjang 66,2 km; 66,8 $\mathrm{km} ; 160,43 \mathrm{~km} ; 43 \mathrm{~km}$ dan 56,4 km (Tabel 1). Jarak tempuh ini diukur dari tempat pengangkutan kayu di tepi hutan hingga ke tempat pengolahan (di pabrik).

Rata-rata produktivitas pengangkutan kayu menggunakan truk Mercedes Benz 2631; Volvo 380; Mitsubishi PS120/135; Mitsubishi PS220/260 dan Hino PS260 masingmasing sebesar $309,540 \mathrm{~m}^{3} \cdot \mathrm{km} / \mathrm{jam} ; 582,487 \mathrm{~m}^{3} \cdot \mathrm{km} / \mathrm{jam} ; 194,148 \mathrm{~m}^{3} \cdot \mathrm{km} / \mathrm{jam} ; 459,660$ $\mathrm{m}^{3} \cdot \mathrm{km} /$ jam dan $465,058 \mathrm{~m}^{3} \cdot \mathrm{km} /$ jam (Tabel 1).

Untuk mengetahui pengaruh jenis truk yang digunakan terhadap produktivitas, pengangkutan kayu dilakukan analisis varian dengan hasil jenis truk berpengaruh sangat nyata (F hitung F Tabel) dengan probabilitas sebesar 0,0001. Ini berarti penggunaan jenis truk merk Mercedes Benz 2631; Volvo 380; Mitsubishi PS120/135; Mitsubishi PS220/260 dan Hino PS260 dapat mempengaruhi tingkat produktivitas pengangkutan yang dihasilkan. Guna 
mengetahui pengaruh jenis truk tersebut secara lebih lanjut dilakukan uji Honestly Significant Difference (HSD) dengan hasil seperti pada Tabel 2. Tabel tersebut menunjukkan bahwa penggunaan 5 jenis truk pengangkut masing-masing menghasilkan produktivitas yang berbeda nyata, kecuali truk Mitsubishi PS220/260 dengan Hino PS260. Truk merk Volvo 380 menghasilkan produktivitas pengangkutan kayu yang paling tinggi dibandingkan jenis truk lainnya, yaitu sebesar 583,722 $\mathrm{m}^{3} . \mathrm{km} / \mathrm{jam}$. Secara umum besar kecilnya produktivitas pengangkutan kayu tergantung pada volume kayu yang diangkut, jarak angkutan dan waktu yang digunakan untuk mengangkut kayu. Semakin sedikit waktu yang diperlukan untuk mengangkut kayu, semakin tinggi pula produktivitas yang dikeluarkan.

\section{Tabel 2. Uji HSD produktivitas pengangkutan kayu}

Table 2. HSD test on productivity of log bauling

\begin{tabular}{|l|c|}
\hline \multicolumn{1}{|c|}{ Jenis truk (Type of truck) } & Produktivitas (Productivity) \\
\hline Mercedes Benz 2631 & $309,540 \mathrm{c}$ \\
\hline Volvo 380 & $583,722 \mathrm{a}$ \\
\hline Mitsubishi PS120/135 & $194,148 \mathrm{~d}$ \\
\hline Mitsubishi PS220/260 & $465,058 \mathrm{~b}$ \\
\hline Hino PS260 & $459,660 \mathrm{~b}$ \\
\hline
\end{tabular}

Keterangan (Remarks): Angka yang diikuti dengan huruf yang berbeda menunjukkan beda nyata (The value followed by different letter means significantly different); nilai HSD (HSD value) $=$ 4,030

Menurut Wackerman (1949), kegiatan pengangkutan kayu dipengaruhi oleh beberapa faktor, yaitu jenis alat angkut, cuaca, kondisi jalan angkutan, tanjakan dan turunan, tikungan serta keterampilan pengemudi. Dalam penelitian ini, tiap operator truk menjalankan truk dengan jenis angkutan, cuaca, kondisi jalan angkutan, tanjakan dan turunan yang relatif sama. Dengan demikian perbedaan produktivitas alat angkut sebagian besar disebabkan olah faktor pengemudi seperti keterampilan, umur dan pengalaman kerja. Keterampilan pengemudi yang rendah tentu akan menghasilkan produktivitas yang rendah juga. Demikian juga operator yang kurang berpengalaman akan menghasilkan produktivitas pengangkutan yang rendah. Sementara itu untuk operator yang berumur relatif lebih tua biasanya mempunyai pengalaman yang lebih banyak akan tetapi tenaganya kurang mendukung, sedang operator yang berumur lebih muda mempunyai kemampuan yang besar, akan tetapi pengalaman yang dimiliki relatif lebih sedikit.

\section{B. Biaya Pengangkutan Kayu}

Dasar perhitungan yang digunakan untuk menghitung biaya pengangkutan kayu dapat dilihat pada Lampiran 1, sedang rumus yang dipakai untuk menghitung biaya pengangkutan kayu sesuai dengan rumus yang tercantum dalam Bab II. Berdasar perhitungan tersebut, biaya pengoperasian alat angkut kayu menggunakan lima jenis truk secara rinci yang dinyatakan dalam Rp/jam dapat dilihat pada Lampiran 2. 
Untuk mengetahui biaya pengangkutan truk yang dikeluarkan, dilakukan dengan jalan membagi biaya operasional truk (Lampiran 1) dengan produktivitas masing-masing jenis alat angkut kayu. Pada Tabel 3 disajikan kisaran dan rata-rata biaya yang dikeluarkan untuk masing-masing jenis alat angkut yang dinyatakan dalam $\mathrm{Rp} / \mathrm{m}^{3} . \mathrm{km}$.

Tabel 3. Biaya pengangkutan kayu menggunakan lima jenis truk $\left(\mathrm{Rp} / \mathrm{m}^{3} \cdot \mathrm{km}\right)$ Table 3. Cost of log hauling using five types of truck $\left(\mathrm{Rp} / \mathrm{m}^{3} . \mathrm{km}\right)$

\begin{tabular}{|c|l|c|c|}
\hline \multirow{2}{*}{ No. } & \multirow{2}{*}{ Jenis truk/Type of truck } & \multicolumn{2}{|c|}{ Biaya/Cost $\left(\mathrm{Rp} / \mathrm{m}^{3} . \mathrm{km}\right)$} \\
\cline { 3 - 4 } & & Kisaran (Range) & Rata-rata (Mean) \\
\hline 1. & Mercedes Benz 2631 & $1.574,144-1.785,200$ & $1.686,553$ \\
\hline 2. & Volvo 380 & $834,651-960,346$ & 949,630 \\
\hline 3. & Mitsubishi PS120/135 & $1.284,481-1.589,570$ & $1.403,864$ \\
\hline 4. & Mitsubishi PS220/260 & $524,672-629,399$ & 619,265 \\
\hline 5. & Hino PS260 & $416,829-736,745$ & 585,165 \\
\hline
\end{tabular}

Pada Tabel 3 tersebut dapat dilihat bahwa rata-rata biaya pengoperasian alat angkut jenis Mercedes Benz 2631; Volvo 380; Mitsubishi PS120/135; Mitsubishi PS220/260 dan Hino PS260 masing-masing sebesar Rp $1.686,553 / \mathrm{m}^{3} \cdot \mathrm{km} ; \mathrm{Rp} 949,630 / \mathrm{m}^{3} . \mathrm{km} ; \mathrm{Rp}$ $1.403,864 / \mathrm{m}^{3} \cdot \mathrm{km} ; \operatorname{Rp} 619,265 / \mathrm{m}^{3} \cdot \mathrm{km}$ dan Rp 585,165/ $\mathrm{m}^{3} \cdot \mathrm{km}$.

Untuk mengetahui pengaruh jenis truk yang digunakan terhadap biaya pengangkutan kayu dilakukan analisis varian dengan hasil jenis truk berpengaruh sangat nyata ( $\mathrm{F}$ hitung $\mathrm{F}$ Tabel) dengan probabilitas 0,0001. Ini berarti penggunaan jenis truk merk Mercedes Benz 2631; Volvo 380; Mitsubishi PS120/135; Mitsubishi PS220/260 dan Hino PS260 dapat mempengaruhi besar kecilnya biaya pengangkutan yang dikeluarkan. Guna mengetahui pengaruh jenis truk tersebut secara lebih lanjut dilakukan uji HSD. Hasil uji HSD selengkapnya dapat dilihat pada Tabel 4. Pada tabel tersebut dapat dilihat bahwa biaya pengangkutan kayu yang dikeluarkan oleh masing-masing jenis truk berbeda nyata kecuali truk merk Mitsubishi PS220/260 dengan Hino PS260. Biaya pengangkutan kayu paling rendah dikeluarkan jika menggunakan truk merk Mitsubishi PS220/260 (Rp 585,165/m²) atau truk merk Hino PS260 (Rp 619,265/ $\mathrm{m}^{3}$ ) sedang biaya pengangkutan paling mahal dikeluarkan jika menggunakan truk merk Mercedes Benz 2631 (Rp 1.686,553/m²). Biaya yang dikeluarkan dalam kegiatan pengangkutan kayu tergantung besar kecilnya produktivitas pengangkutan yang dikeluarkan. 
Tabel 4. Uji HSD biaya pengangkutan kayu

Table 4. HSD test on cost of log bauling

\begin{tabular}{|l|c|}
\multicolumn{1}{|c|}{ Jenis truk (Type of truck) } & $\begin{array}{c}\text { Biaya } \\
\text { (Cost) }\end{array}$ \\
\hline Mercedes Benz 2631 & $1686,553 \mathrm{a}$ \\
\hline Volvo 380 & $893,769 \mathrm{c}$ \\
\hline Mitsubishi PS120/135 & $1403,864 \mathrm{~b}$ \\
\hline Mitsubishi PS220/260 & $585,165 \mathrm{~d}$ \\
\hline Hino PS PS260 & $619,265 \mathrm{~d}$ \\
\hline
\end{tabular}

Keterangan (Remarks) : Angka yang diikuti dengan huruf yang berbeda menunjukkan beda nyata (The value that be followed by different letter means significantly different); nilai HSD (HSD value) $=4,030$

\section{Efisiensi Waktu Pengangkutan Kayu}

Tingkat efisiensi waktu pengangkutan kayu menggunakan lima jenis truk dapat dilihat pada Tabel 5. Di situ terlihat bahwa rata-rata tingkat efisiensi waktu pengangkutan kayu dengan truk jenis Mercedes Benz 2631; Volvo 380; Mitsubishi PS120/135; Mitsubishi PS220/260 dan Hino PS260 berturut-turut sebesar antara 76,69\%; 79,26\%; 87,42\%; 77,92\% dan $73,40 \%$ (Tabel 5).

Tabel 5. Tingkat efisiensi waktu pengangkutan kayu menggunakan lima jenis truk Table 5. The degree of time efficiency of log bauling using five types of truck

\begin{tabular}{|c|l|l|c|}
\hline \multirow{2}{*}{ No } & \multirow{2}{*}{ Jenis truk (type of truck) } & \multicolumn{2}{|c|}{ Tingkat efisiensi (\%) } \\
\cline { 3 - 4 } & & Kisaran (Range) & Rata-rata (Mean) \\
\hline 1. & Mercedes Benz 2631 & $76,314-77,502$ & 76,69 \\
\hline 2. & Volvo 380 & $78,497-79,679$ & 79,26 \\
\hline 3. & Mitsubishi PS120/135 & $86,83-87,19$ & 87,42 \\
\hline 4. & Mitsubishi PS220/260 & $74,96-81,79$ & 77,92 \\
\hline 5. & Hino PS260 & $69,65-76,02$ & 73,40 \\
\hline
\end{tabular}

Keterangan (Remarks) : Jumlah pengamatan (number of replicates) $=47$ 
Untuk mengetahui pengaruh jenis truk yang digunakan terhadap efisiensi waktu pengangkutan kayu dilakukan analisis varian dengan hasil jenis truk berpengaruh sangat nyata (F hitung F Tabel) dengan probabilitas 0,0001 . Ini berarti bahwa jenis truk yang digunakan dalam kegiatan pengangkutan kayu berpengaruh nyata terhadap efisiensi waktu pengangkutan kayu. Guna mengetahui pengaruh jenis truk tersebut secara lebih lanjut dilakukan uji HSD. Hasil uji HSD selengkapnya dapat dilihat pada Tabel 6. Di situ dapat dilihat bahwa penggunaan truk merk Mitsubishi PS120/135 menghasilkan efisiensi waktu pengangkutan kayu yang paling tinggi dibandingkan jenis truk lainnya, yaitu sebesar $86,99 \%$. Sementara itu penggunaan truk merk Mercedes Benz 2631, Volvo 380 dan Mitsubishi PS220/260 tidak berbeda nyata. Ini berarti, penggunaan ke tiga jenis truk angkut tersebut menghasilkan efisiensi waktu pengangkutan yang relatif sama (tidak jauh berbeda).

Besar kecil tingkat efisiensi waktu pengangkutan kayu dipengaruhi oleh besar kecilnya waktu efektif yang digunakan. Semakin efektif waktu yang digunakan untuk mengangkut kayu, semakin tinggi pula tingkat efisiensinya. Besar kecilnya waktu efektif tersebut tergantung pada keterampilan dan pengalaman operator di lapangan. Oleh karena itu untuk meningkatkan efisiensi pengangkutan kayu, waktu efektif yang digunakan untuk mengangkut kayu sedapat mungkin diperkecil.

Tabel 6. Uji HSD efisiensi waktu pengangkutan kayu

Table 6. HSD test on time efficiency of log bauling

\begin{tabular}{|l|c|}
\hline \multicolumn{1}{|c|}{ Jenis truk (Type of truck) } & Efisiensi (Efficiency) \\
\hline Mercedes Benz 2631 & $76,98 \mathrm{~b}$ \\
\hline Volvo 380 & $79,26 \mathrm{~b}$ \\
\hline Mitsubishi PS120/135 & $86,99 \mathrm{a}$ \\
\hline Mitsubishi PS220/260 & $77,92 \mathrm{~b}$ \\
\hline Hino PS260 & $73,40 \mathrm{c}$ \\
\hline
\end{tabular}

Keterangan (Remarks) : Angka yang diikuti dengan huruf yang berbeda menunjukkan beda nyata (The value that be followed by different letter means significantly different); nilai HSD (HSD value) $=4,030$

Selanjutnya, untuk mengetahui jenis truk mana yang mempunyai prestasi optimum dilakukan uji optimum, yaitu mencari nilai maksimal hasil penjumlahan nilai-nilai abjad yang mengikuti angka pada masing-masing jenis truk seperti tercantum dalam Tabel 2, 4 dan 6. Hasil rekapitulasi uji optimum tersebut disajikan pada Tabel 7. 
Tabel 7. Uji optimum pengangkutan kayu menggunakan lima jenis truk Table 7. Optimum test of log bauling using five types of truck

\begin{tabular}{|l|c|c|c|c|c|c|c|}
\hline \multirow{2}{*}{$\begin{array}{c}\text { Jenis truk } \\
\text { (Type of truck) }\end{array}$} & $\begin{array}{c}\text { Produktivitas } \\
\text { (Productivity) } \\
(1)\end{array}$ & \multicolumn{2}{|c|}{$\begin{array}{c}\text { Biaya } \\
\text { (Cost) } \\
(2)\end{array}$} & \multicolumn{2}{c|}{$\begin{array}{c}\text { Efisiensi } \\
\text { (Efficiency) } \\
(3)\end{array}$} & $\begin{array}{c}\text { Jumlah } \\
\text { (Total) } \\
(1)+(2)+(3) \\
(4)\end{array}$ \\
\cline { 2 - 8 } & $\mathrm{G}$ & $\mathrm{S}$ & $\mathrm{G}$ & $\mathrm{S}$ & $\mathrm{G}$ & $\mathrm{S}$ & $\begin{array}{c}\text { G } \\
\text { Mercedes Benz 2631 }\end{array}$ \\
\hline Volvo 380 & $\mathrm{c}$ & 4 & $\mathrm{a}$ & 1 & $\mathrm{~b}$ & 3 & 6 \\
\hline Mitsubishi PS120/135 & $\mathrm{d}$ & 1 & $\mathrm{~b}$ & 2 & $\mathrm{a}$ & 4 & 7 \\
\hline Mitsubishi PS220/260 & $\mathrm{b}$ & 3 & $\mathrm{~d}$ & 4 & $\mathrm{~b}$ & 3 & 10 \\
\hline Hino PS260 & $\mathrm{b}$ & 3 & $\mathrm{~d}$ & 4 & $\mathrm{c}$ & 2 & 9 \\
\hline
\end{tabular}

Keterangan (Remarks) : G = tingkatan (grade); S = nilai (score)

Pada kolom (1) atau produktivitas dan kolom (3) atau efisiensi dalam Tabel 7 tersebut, masing-masing abjad mempunyai nilai sebagai berikut: $a=4 ; b=3 ; c=2$; dan $d=1$, sedang untuk kolom (2) atau biaya dalam Tabel 7, masing-masing abjad mempunyai nilai sebagai berikut: $\mathrm{a}=1 ; \mathrm{b}=2 ; \mathrm{c}=3$; dan $\mathrm{d}=4$.

Berdasarkan Tabel 7 pada kolom (4) dapat dilihat bahwa hasil penjumlahan nilai-nilai uji optimum pada masing-masing jenis truk berkisar antara 6-10. Nilai terendah, yaitu 6 ditemukan pada jenis truk Mercedes Benz 2631, sedang yang paling tinggi, yaitu 10 ditemukan pada jenis truk Volvo 380 dan Mitsubishi PS220/260. Ini berarti penggunaan truk merk Volvo 380 dan Mitsubishi PS220/260 untuk mengangkut kayu menghasilkan prestasi kerja (produktivitas, biaya dan efisiensi waktu pengangkutan) yang paling optimum sedang penggunaan truk merk Mercedes Benz 2631 kurang optimum. Jika dilihat berdasarkan besarnya nilai yang dimiliki, truk merk Volvo 380 mempunyai prestasi yang tinggi dalam menghasilkan produktivitas pengangkutan kayu (nilai 4, lihat Tabel 7), sedang truk merk Mitsubishi PS220/260 mempunyai prestasi yang tinggi dalam hal biaya pengangkutan yang rendah (nilai 4, lihat Tabel 7). Dengan demikian dapat dikatakan bahwa penggunaan truk merk Volvo 380 dan Mitsubishi PS220/260 untuk mengangkut kayu lebih disarankan karena menghasilkan prestasi yang optimum. Namun demikian penggunaan truk jenis lain masih banyak ditemukan di lapangan dengan beberapa pertimbangan, yaitu:

1. Truk berdaya muat lebih kecil (seperti truk merk Mercedes Benz 2631 dan Mitsubishi PS120/135) pada umumnya lebih mudah dan lincah dioperasikan di jalan hutan yang kondisi jalannya banyak tanjakan dan tikungan. Truk jenis ini banyak dimiliki perusahaan HTI, sedang truk berkapasitas lebih besar biasanya merupakan truk sewaan.

2. Truk berkapasitas lebih besar (seperti Volvo 380, Mitsubishi PS220/260 dan Hino PS260) tidak diperbolehkan melewati jalan umum milik negara karena harus memenuhi persyaratan batas maksimal muatan. Truk jenis ini biasanya melewati jalan angkutan yang sudah dipersiapkan perusahaan (logging truck) di dalam hutan. 


\section{Pembahasan Umum}

Berdasar pengamatan di lapangan dan hasil wawancara dengan operator truk pengangkut kayu, kriteria jalan angkutan kayu yang baik adalah jalan yang permukaannya relatif rata, lebar jalan cukup untuk papasan dua truk yang sedang bergerak, jumlah turunan dan tanjakan tidak banyak dengan kemiringan yang tidak besar, pandangan leluasa tidak banyak penghalang. Di samping itu, operator truk lebih menyukai jarak angkut yang tidak terlalu jauh.

Lebar jalan angkutan berkisar antara 8-12 m sedang jalan cabang berkisar antara 6-8 m. Menurut Tinambunan (1991), membangun banyak jalan cabang berarti mengurangi biaya total pembangunan jalan tetapi akan meningkatkan biaya pengangkutan (bauling). Jalan angkutan digunakan hanya pada saat cuaca tidak turun hujan, karena jika turun hujan, jalan angkutan menjadi becek dan licin, bahkan jika dipaksakan mengangkut kayu pada saat hujan, truk bisa terjerembab di jalan yang memang tidak diperkeras secara khusus tersebut. Akibat jangka panjangnya, jalan angkutan menjadi rusak karena bekas roda truk yang terjerembab meninggalkan bekas lubang yang lebar dan dalam sehingga semakin sulit dilalui.

Persyaratan lain yang menyangkut layak tidaknya jalan angkutan kayu digunakan adalah adanya tanjakan maksimal sebesar $12 \%$, permukaan jalan yang tidak diperkeras secara khusus dapat diganti dengan memadatkan permukaan jalan dan memeliharanya secara berkala sehingga permukaan jalan tetap rata dan drainase lancar serta terawat dengan baik. Selain itu juga dibuat tebang bayang selebar 20-25 m di kiri dan kanan jalan dengan tujuan agar pengemudi truk mendapatkan ruang pandang yang bebas tanpa halangan, jalan mendapat pencahayaan yang cukup dan untuk mempercepat pengeringan permukaan jalan bila terkena hujan. Pembuatan saluran drainase di kanan kiri badan jalan juga diperlukan untuk memperlancar aliran air.

\section{KESIMPULAN DAN SARAN}

\section{A. Kesimpulan}

Berdasarkan hasil penelitian dapat disimpulkan sebagai berikut:

1. Produktivitas pengangkutan dengan truk jenis Volvo 380, Mitsubishi PS220/260, Hino PS260, Mercedes Ben₹ 2631 dan Mitsubishi PS120/135 berturut-turut sebesar 582,508 $\mathrm{m}^{3} \mathrm{~km} / \mathrm{jam} ; 465,058 \mathrm{~m}^{3} \mathrm{~km} / \mathrm{jam}, 459,660 \mathrm{~m}^{3} \mathrm{~km} / \mathrm{jam} ; 309,540 \mathrm{~m}^{3} \mathrm{~km} / \mathrm{jam}$ dan 194,148 $\mathrm{m}^{3} \mathrm{~km} / \mathrm{jam}$.

2. Biaya pengangkutan kayu menggunakan truk jenis Mitsubishi PS220/260, Hino PS260, Volvo 380, Mitsubishi PS120/135 dan Mercedes Benz 2631 berturut-turut sebesar Rp $585,165 / \mathrm{m}^{3} \cdot \mathrm{km} ; \mathrm{Rp} 619,265 / \mathrm{m}^{3} \cdot \mathrm{km} ; \mathrm{Rp} 949,630 / \mathrm{m}^{3} \cdot \mathrm{km} ; \mathrm{Rp} 1.403,864 / \mathrm{m}^{3} \cdot \mathrm{km}$ dan Rp $1.686,553 / \mathrm{m}^{3} \cdot \mathrm{km}$.

3. Efisiensi waktu pengangkutan kayu dengan truk Mitsubishi PS120/135, Volvo 380, Mitsubishi PS220/260, Mercedes Benz 2631 dan Hino PS260 berturut-turut sebesar 87,42\%; $79,26 \% ; 77,92 \%$.,76,69\% dan $73,40 \%$.

4. Produktivitas pengangkutan tertinggi dicapai bila menggunakan truk merk Volvo 380 yaitu sebesar 582,508 $\mathrm{m}^{3} \mathrm{~km} / \mathrm{jam}$, sedang biaya pengangkutan yang paling rendah 
menggunakan truk merk Mitsubishi PS 220/260 atau Hino PS260, yaitu masing-masing sebesar Rp 585,165/ $\mathrm{m}^{3} . \mathrm{km}$ dan Rp $619,265 / \mathrm{m}^{3} . \mathrm{km}$. Efisiensi waktu pengangkutan kayu yang tertinggi menggunakan truk merk Mitsubishi PS 220/260 yaitu sebesar 87,42\%.

5. Penggunaan truk merk Volvo 380 dan Mitsubishi PS220/260 untuk mengangkut kayu menghasilkan prestasi yang optimum dalam hal produktivitas, biaya dan efisiensi pengangkutan.

\section{B. Saran}

1. Truk merk Volvo 380 dan Mitsubishi PS220/260 disarankan digunakan untuk mengangkut kayu di HTI, namun demikian penggunaan truk berkapasitas kecil masih dimungkinkan karena lebih lincah dan mudah dioperasikan di lapangan.

\section{DAFTAR PUSTAKA}

Anonim. 1974. Logging and log transport in tropical high forest. FAO Forestry Development Paper No 18, Rome.

. 1992. Cost control in forest harvesting and road contruction. FAO Forestry Development Paper No 99, Rome

Dulsalam \& Arifin S. 1977. Efisiensi pengangkutan dan muat bongkar kayu di suatu pengusahaan hutan di Kalimantan. Buletin Penelitian Hasil Hutan Vol 15 (1). Pusat Penelitian dan Pnegembangan Hasil Hutan. Bogor.

Dulsalam \& Sukanda. 1989. Studi kasus produktivitas dan biaya angkutan dengan truk Izusu di dua HPH di Sumatera Barat. Jurnal Penelitian Hasil Hutan Vol.6 No1. Pusat Penelitian dan Pengembangan Hasil Hutan. Bogor.

Elias. 1988. Pembukaan wilayah hutan. Fakultas Kehutanan Institut Pertanian Bogor, Bogor.

Sianturi, A. 1981. Produktivitas dan biaya angkutan dengan truk Izusu pada beberapa perusahaan Kehutanan di Jambi dan Riau. Laporan balai Penelitian Hasil Hutan No. 156. Balai Penelitian Hasil Hutan, Bogor.

Sianturi, A. dan D. Tinambunan. 1985. Produktivitas angkut truk dan truk semi trailer di Sumatera dan Kalimantan Selatan. Jurnal Penelitian Hasil Hutan Vol. 2 No 1. Pusat Penelitian dan Pengembangan Hasil Hutan. Bogor.

Sukanda, Dulsalam \& Ishak Sumantri. 1989. Produktivitas dan biaya pengangkutan tiga jenis truk angkutan kayu di tiga Hak Pengusahaan Hutan di Kalimantan Barat. Jurnal Penelitian Hasil Hutan Vol 6 No 4. Pusat Penelitian dan Pengembangan Hasil Hutan. Bogor.

Tinambunan, D. 1991. Praktek pembuatan jalan hutan dan permasalahannya di daerah provinsi Jambi. Jurnal Penelitian Hasil Hutan Vol. 9 No 4. Pusat Penelitian dan Pengembangan Hasil Hutan. Bogor.

Wackerman, A. E. 1949. Harvesting timber crops. Mc Graw-Hill Book Company, New York. 